\title{
EDUCAÇÃO AMBIENTAL: O DESPERTAR DE UMA PROPOSTA CRÍTICA PARA A FORMAÇÃO DO SUJEITO ECOLÓGICO
}

\author{
L. O. Silva ${ }^{1}$ e A. P. L. Costa ${ }^{1}$ e E. A. Almeida ${ }^{2}$ \\ ${ }^{1}$ Diretoria de Recursos Naturais - IFRN e ${ }^{2}$ Depto de Ecologia - UFRN \\ le.biology@gmail.com
}

Artigo submetido em outubro/2011 e aceito em março/2012

\section{RESUMO}

Este artigo aborda questões em torno da história e epistemologia da Educação Ambiental no Brasil, bem como apresenta os pressupostos para o desenvolvimento de uma Educação Ambiental crítica, transformadora e emancipatória. Este estudo realiza-se no momento em que os problemas socioambientais tomam proporções planetárias ao mesmo tempo em que desencadeiam discussões de amplitude global. No âmbito desse contexto social atual no qual a educação constitui-se como uma forma de intervenção no mundo, diversas formulações teórico-metodológicas remetem-se à consolidação de tendências em Educação Ambiental como meio de enfrentamento dos desafios postos pela crise ambiental.

PALAVRAS-CHAVE: Educação Ambiental, Meio ambiente, Práxis pedagógica.

\section{ENVIRONMENTAL EDUCATION: AWAKENING TO A CRITICISM PROPOSAL FOR TRAINING OF SUBJECT ECOLOGICAL}

\section{ABSTRACT}

This article approaches questions around history and epistemology of the Environmental Education in Brazil. It presents the estimated ones for a critical, transformer and emancipation Environmental Education. This study occurs in a where social and environmental problems reach great dimensions and provoke discussions all over the planet. Inside this social context where education is taken as a form intervention in the world, several methodological and theoretical approaches emerge indicating Environmental Education tendencies as different ways to face challenges due to environmental crisis.

KEY-WORDS: Environmental Education, Environmental, Pedagogical Praxis. 


\section{EDUCAÇÃO AMBIENTAL: O DESPERTAR DE UMA PROPOSTA CRÍTICA PARA A FORMAÇÃO DO SUJEITO ECOLÓGICO}

\section{INICIANDO O DEBATE}

Este artigo remete-se a discussão em torno da genealogia da Educação Ambiental (EA), principalmente no Brasil, bem como apresenta fundamentos epistemológicos constitutivos das principais correntes do campo da EA. Visitando autores importantes sobre o assunto, fazemos um esforço para resgatar os antecedentes históricos e políticos que abriram as portas para a consolidação da EA no Brasil e a constituição de várias correntes no campo.

Partimos da conviç̧ão de que a EA que vem se consolidando no Brasil é parte integrante de um movimento bem mais amplo e, portanto, histórico sobre a questão ambiental no mundo. A EA é a herdeira mais próxima dos debates ecológicos e está dentro dos movimentos de constituição de alternativas contra-hegemônicas que visam à construção de outras maneiras de relação sociedade-natureza.

Se a EA se constitui como parte do movimento ecológico, é importante fazer uma breve releitura sobre importantes acontecimentos históricos e políticos que marcaram a trajetória da preocupação humana com as questões ambientais, tanto no campo da ciência, como do movimento ambientalista, para melhor situar a atmosfera genealógica da EA.

\section{MOVIMENTO ECOLÓGICO: PORTAS ABERTAS PARA A EDUCAÇÃO AMBIENTAL}

As críticas contundentes em relação ao modelo de desenvolvimento econômico começaram a se intensificar em meados dos anos 1960, sendo exibidas ao mundo, no plano social e político da época, as conseqüências do modelo de desenvolvimento econômico capitalista adotado, principalmente, pelos países ditos desenvolvidos.

O terreno antecessor ao surgimento da EA é o momento em que a década de 1960 começava exibir ao mundo as conseqüências do modelo de desenvolvimento econômico adotado pelos países ricos, que se traduzia em níveis crescentes de poluição atmosférica nos grandes centros urbanos, a exemplo de cidades como Los Angeles, Nova lorque, Berlim, Chicago, Tóquio e Londres. Ainda na década de 1950, especificamente em 1953, um acidente em Minamata, Japão, causou a contaminação, por mercúrio, de milhares de pessoas. No inicio dos anos 1960 já se destacavam alguns rios envenenados por despejos industriais, como os casos dos rios Tâmisa, Sena, Danúbio, Mississipi, Tietê e outros; a perda da cobertura vegetal da terra, ocasionando erosão, perda da fertilidade do solo, assoreamento dos rios, inundações, movimentos populacionais, além de pressões crescentes sobre a biodiversidade. Nessa época, o meio ambiente já mostrava sintomas de uma grave crise que viria se alastrar pelo globo, nas décadas subseqüentes.

Dias (2004, p. 77) lembra que "os recursos hídricos, sustentáculo e derrocada de muitas civilizações, estavam sendo comprometidos a uma velocidade sem precedentes na história 
humana. A imprensa mundial registrava essa situação, em manchetes dramáticas". Tudo isso se desdobrava em ritmos bem acelerados, jamais vistos na história humana. Essas conseqüências fizeram emergir várias inquietações sobre a problemática socioambiental.

Nesse aspecto, vale apenas mencionar a denúncia da jornalista Rachel Carson, em seu livro Silent Spring (primavera silenciosa) publicado em 1962. O livro alertava para uma série de questões sobre as conseqüências ambientais promovidas pelo modelo econômico então vigente, sendo a temática em discussão do livro objeto de inquietação política de âmbito internacional. O livro fomentou uma discussão internacional sobre a perda da qualidade de vida, chegando a ter suas edições esgotadas por diversas vezes.

Gonçalves (2002, p. 138) destaca o fato de que o "ambientalismo como movimento políticocultural, emergiu mesmo nos anos 1960". O ideário de lutas ambientais teve origem subjacente ao momento da história recente em que o sonho e a utopia para transformar o mundo ganhava fôlego e estava em alta acumulando energias com vistas a uma possível radicalização das transformações sociais.

Nesse sentido, discutir o ambientalismo sem associá-lo "ao ambiente utópico que lhe deu origem e à sua filiação contracultural seria reduzir a compreensão daquilo que fundamentalmente o inspira e lhe confere poder de atração e convocação à ação" (CARVALHO, 2006, p. 48). Nesse período, vivia-se em questionamentos permanentes da ordem social vigente, como os movimentos eclodidos na Europa, Estados Unidos e América Latina. Período do surgimento dos Movimentos contraculturais, de esquerda, etc., cujos traços mais expressivos foram identificados no movimento estudantil do maio francês de 1968 com as chamadas "barricadas do desejo", nos movimentos contra a guerra do Vietnã, contra a guerra fria e a corrida armamentista/nuclear era o momento em que ascendia grandes movimentos como o dos hippies, o movimento negro americano - Black Power - o movimento pacifista, além da liberação sexual, das drogas e o rock-and-roll. Como reconhece Gonçalves (2002, p. 142), "o ambientalismo é filho direto do movimento da contracultura". O movimento contracultural emergido na década de 1960 também é reconhecido por Lima $(2005$, p. 30$)$ como

um último elemento impulsionador da nova problematização da questão ambiental assim como da mobilização social em sua defesa se expressa através do Movimento de Contracultura, que emergiu inicialmente na sociedade norte-americana nos anos 60 do século passado, e se irradiou gradualmente e com intensidades variáveis, para o restante dos países ocidentais, tanto no norte quanto no sul.

O movimento de contracultura constituía uma ampla crítica aos valores e normas da sociedade capitalista ocidental em ascensão. Combatia o consumismo, os agravos ambientais oriundos do industrialismo, a exploração do trabalho, a ordem da família patriarcal, o racismo, a guerra, entre outras questões, que definiam o pensamento da sociedade capitalista 
ocidental. Nesse mesmo período, na América Latina, visualizava-se o aparecimento das esquerdas e em suas respostas às imposições de regimes repressivos e ditatoriais militares.

Nesse cenário social, se consolidou as bases iniciais para o ecologismo político e suas influências impulsionadoras da Educação Ambiental. Nesse aspecto, o movimento ecológico emergido desse contexto abriu as portas para a Educação Ambiental.

\section{A INSTITUCIONALIZAÇÃO DA EDUCAÇÃO AMBIENTAL NO BRASIL}

No Brasil, a EA também é parte do movimento ecológico emergente dos anseios e necessidades da sociedade por um mundo mais equânime. Os itinerários da EA no Brasil se desdobraram logo após o contexto social e político caracterizado pela repressão ditatorial emergida no país a partir de 1964, encerrando-se, ao menos oficialmente, em 1985. Quanto a esse período da história brasileira, Germano (1994, p. 94) afirma:

a sociedade brasileira, no período 1964-1985, atravessou ciclos de repressão e de liberalização política, que eram reflexos das lutas de classe, da correlação de forças entre o Estado e os setores oposicionistas da sociedade civil, bem como das contradições inerentes ao próprio bloco no poder, ou seja, dos conflitos existentes entre as diversas facções militares e das classes dominantes.

Esse era o cenário da sociedade brasileira no momento em que se iniciava a ascensão da EA no Brasil.

O cenário social da América Latina, em meados da década de 1970, era de efervescência pelos regimes militares ditatoriais, a exemplo do Brasil, Argentina e Chile. No caso do Brasil, a resistência armada ao regime estava praticamente controlada, o Brasil iniciava o seu processo de crescimento com a proposta do milagre econômico, a Rede Globo de Televisão emergia com seu império, conquistando milhões de telespectadores com suas novelas e o telejornal inculcando a ideologia dominante. O Brasil ganhava, pela terceira vez, a copa do mundo de futebol, ao mesmo tempo em que expandia ideologias nacionalistas do tipo Brasil: ame-o ou deixe-o ou com a expressão esse é um país que vai pra frente. No ritmo do milagre econômico, o regime militar contraria as preocupações internacionais de proteção ao meio ambiente e privilegia o crescimento econômico, a qualquer custo, sem nenhuma preocupação ambiental, como o caso da construção da rodovia Transamazônica, motivada por razões de "desenvolvimento" e de segurança nacional.

Tanto no Brasil como na América Latina, a década de 1970 é marcada por contextos de lutas pela democracia e contra regimes ditatoriais repressivos, sendo, no contraste, um período importante para o ambientalismo.

Nessa época, em que também se desdobrou a expansão dos meios de comunicação de massa e o surgimento de uma classe média urbana, como também de segmentos da sociedade formadores de opinião, surgiram as condições objetivas para a expansão e constituição de várias entidades do setor ambientalista que floresceram nas décadas subseqüentes. Sob a 
liderança de Chico Mendes configura-se uma luta de caráter nacional e o movimento ambientalista adquire feições e projeções internacionais.

No que concerne às primeiras políticas públicas para EA no Brasil, elas só foram sinalizadas a partir de 1980, especificamente, na Lei 6.902, de abril de 1981, que estabeleceu novos tipos de áreas de preservação ambiental, entre as quais as Estações Ecológicas, destinadas à realização de pesquisas básicas e aplicadas de Ecologia, à proteção do ambiente natural e ao desenvolvimento da educação conservacionista'. No mesmo ano foi promulgada a primeira Lei 6.938/81 que põe a EA como um instrumento para ajudar a solucionar problemas ambientais, sendo a primeira lei para assegurar que a EA fosse incluída em todos os níveis de ensino. Como direito de todos e dever do Estado, a EA é incluída no capítulo VI, artigo 225 da Constituição Federal de 1988, que trata da questão ambiental, assegurando a promoção da EA em todos os níveis de ensino e a conscientização pública para a preservação do meio ambiente e, no ano seguinte, o governo criaria o Instituto Brasileiro do Meio Ambiente e dos Recursos Naturais Renováveis - IBAMA.

No campo científico, também é parte do movimento de construção da EA a geração que tenta construir um locus acadêmico para a EA, e, nesse sentido, tem como representante o Grupo de Estudos em EA da Associação Nacional de Pós-Graduação em Educação - ANPEd, aprovado em 2002 e a Associação Nacional de Pesquisa e Pós-Graduação em Ambiente e Sociedade ANPPAS, em que a temática da Educação Ambiental vem contemplada em um Grupo de Trabalho. Destaca-se ainda a consolidação do primeiro Mestrado em Educação Ambiental reconhecido pela Coordenação de Aperfeiçoamento de Pessoal de Nível Superior - CAPES, iniciado em 1994, na Fundação Universidade Federal do Rio Grande - FURG. "Esta geração vem à frente da criação de Programas de Pós Graduação e linhas de pesquisa para a EA e que é responsável por uma produção teórica crescente" (GUIMARÃES, 2003, p. 3).

\section{A DIVERSIDADE EPISTEMOLÓGICA DA EDUCAÇÃo AMBIENTAL E UMA PROPOSTA TRANSFORMADORA}

Tem sido comum encontrar autores que assumem a posição de que a EA desenvolve-se a partir de práticas diversificadas. No campo da educação, várias experiências pedagógicas em EA estão se consolidando hoje em todo o mundo sob a perspectiva de diversas concepções e matrizes teóricas como categorias conceituais estruturantes. Nesse contexto conjuntural, a EA consolida-se à margem de uma prática homogênea e consensual no que tange aos seus fundamentos teóricos e epistemológicos. Nesse sentido, partimos da "compreensão de que o campo da educação ambiental é um campo plural, diverso e diferenciado de tendências político-pedagógicas, éticas e epistemológicas" (LIMA, 2005, p. 20).

Por muitas razões, Loureiro (2006, p. 132) argumenta que "a Educação Ambiental integra propostas educativas oriundas de concepções teóricas e matrizes ideológicas distintas, sendo reconhecida no Brasil como de inegável relevância para a construção de uma perspectiva 
ambientalista de mundo e de sociedade". Atribuindo o mesmo sentido, Guimarães (2006, p. 11) também concorda que "hoje não é mais possível afirmar que se faz Educação Ambiental sem qualificá-la. Já não é mais suficiente falar de uma Educação Ambiental genérica, conjugada no singular". Seguindo a mesma linha de raciocínio que verifica a diversidade epistemológica no campo da EA, Sauvé (2005, p. 17) reforça essa convicção:

quando se aborda o campo da educação ambiental, podemos nos dar conta de que, apesar de sua preocupação comum com o meio ambiente e do conhecimento do papel central da educação para a melhoria da relação com este último, os diferentes autores (pesquisadores, professores, pedagogos, animadores, associações, organismos, etc.) adotam diferentes discursos sobre a EA e propõem diversas maneiras de conceber e de praticar a ação educativa neste campo.

São diversas as posturas pedagógicas, que vêm se constituindo como práticas voltadas para a dimensão ambiental e que reivindicam se consolidar como representantes legítimas da EA. Nesse aspecto, o que poderia vir a ser contribuição para a construção de diretrizes epistemológicas para a EA torna-se fragmentação de uma construção coletiva em busca dos fundamentos da EA.

Layrargues (2002, p. 88) chama a atenção para esse aspecto. Nesse sentido, comenta:

aquilo que já era consagrado como "educação ambiental", alguns educadores resolveram atualmente renomear com novos termos definidores. Surgiram então, no Brasil e no mundo, novas adjetivações para a prática educativa relativa ao meio ambiente na década de 90: além da educação ambiental, fala-se agora em educação para o desenvolvimento sustentável, Neal (1995), Ecopedagogia, Gadotti (1997), educação para a cidadania, Jacobi (1997a) e finalmente, educação para a gestão ambiental, Quintas e Gualba (1995).

A essas novas adjetivações no campo da EA acrescentaríamos ainda a Ecoalfabetização, Capra (1993).

Quanto à proliferação de novas adjetivações no campo da $E A$, alertamos para a necessidade de uma reflexão para a compreensão dessa questão: em primeiro lugar, a substituição da EA por essas novas adjetivações seria um retrocesso, pois, "para se praticar uma educação voltada a formação e ao exercício da cidadania não é necessário que se altere o nome de uma prática consagrada, já que ela contempla esta dimensão" (LAYRARGUES, 2002, p. 103).

Tais experiências pedagógicas estão sendo desenvolvidas em diferentes lugares e aportandose em concepções teóricas metodológicas diversas, que ora se entrelaçam e ora divergem. Assim, se circunscrevem nas disputas conceituais em busca de novas identidades.

Nesse contexto, identificamos a existência de caminhos de EA com interesses e objetivos diversificados. Quanto a esse aspecto, Lima (2002, p. 120) identifica que "alguns os trilham conscientemente, mas a maioria orienta-se pela desinformação, ora pelos apelos do discurso oficial promovido pela ideologia dominante dentro do campo". Portanto, é importante demonstrar que essas práticas não compartilham dos mesmos valores, objetivos e ideologias, pois apresentam-se permeadas por diferenças essenciais com relação aos meios e fins da EA 
que se iniciam no próprio debate interno da educação. Nesse sentido, é importante destacar a observação de Lima (2002, p. 120):

os debates internos ao campo da educação acompanham os macrodebates sociais e lhes são tributários; além disso, apresentam o mesmo espectro de valores, interesses e ideologias que caracterizam sua diversidade. São esses macrodebates político-ideológicos e filosóficos, relativos aos modelos concorrentes de desenvolvimento, que acabam por orientar as definições nos planos educacional, tecnológico, científico, produtivo e trabalhista, entre outros.

Essa compreensão demonstra que o processo educativo não é neutro, desprovido de interesses e objetivos diversos, tanto individuais como coletivos. É, portanto, um veículo pelo qual também atravessa a disputa pela conservação ou transformação das condições sociais (LAYRARGUES, 2006, p. 95).

Diante da diversidade epistemológica da EA, é importante compreender os propósitos políticos, ideológicos e éticos explícitos e implícitos em cada uma dessas correntes de forma que possamos perceber a capacidade delas promoverem, de fato, mudanças significativas em relação aos agravos ambientais e sociais e em nossas vidas individuais e coletivas.

A essa altura passamos a refletir em tomo das principais matrizes teóricas orientadoras da vasta diversidade de posturas pedagógicas em EA, a partir de critérios por nós caracterizados como diferenciadores dessas tendências.

Para identificar as principais tendências pedagógicas em EA buscamos alguns critérios diferenciadores das matrizes teóricas nesse campo, conforme Lima (2002), Loureiro et al (2002b; 2006), Loureiro (2004), que consideram: 1) perspectiva de mudança social para indicar o potencial de transformação ou conservação em cada uma das matrizes; 2) perspectiva que propõe mudanças significativas coletivas ou individuais; 3) nível de problematização ou reducionismo na abordagem sobre as questões do meio ambiente, da sociedade e da educação.

Iniciaremos nossa análise pela corrente que vem hegemonizando o campo da EA, identificada por nós como tendência fundamentada principalmente por uma compreensão naturalista e conservacionista do meio ambiente e da crise ambiental, por adotar uma visão reducionista, de caráter biologizante ou fragmentada da questão ambiental, que enxerga o ambiente como algo exterior que rodeia a vida humana e desconsidera a interdependência das relações sociais com o meio ambiente.

Ao caminhar pelas trilhas da EA, no que diz respeito ao contato com sua teorização ao longo dos últimos anos, isto é, a partir do levantamento bibliográfico, tem sido muito comum perceber a cor verde como cor de destaque na maioria das capas dos livros direcionados as discussões sobre questões ambientais. Isso talvez seja ainda reflexo de uma visão naturalista no entendimento do campo ambiental. De fato, a EA emergiu no âmbito de uma concepção 
de meio ambiente restrita às dimensões de cunho meramente naturalistas. Nesse aspecto, Carvalho 2006 reconhece que a:

EA surge em um terreno marcado por uma tradição naturalista. Superar essa marca, mediante a afirmação de uma visão socioambiental, exige um esforço de superação de dicotomia entre natureza e sociedade, para poder ver as relações de interação permanente entre a vida humana social e a vida biológica da natureza (CARVALHO, 2006, p. 37).

Essa concepção que separa a natureza da cultura filia-se e fundamenta-se numa perspectiva naturalista. E, por sua vez, essa visão "naturalista" compreende a natureza desconsiderando a relação do mundo cultural humano com o meio físico, percebe a natureza como uma ordem apenas biológica, essencialmente boa, pacífica, equilibrada e harmônica nas suas interações sistêmicas.

A visão que separa a natureza do homem e da cultura humana é decorrente de uma razão civilizacional, a qual serviu de base para a exploração da natureza enquanto recurso, que justificou, em termos ideológicos, a escravidão e constituiu também a sociedade racista.

Em Origens do totalitarismo Hannah Arendt (1989) comenta que quando os bôeres australianos chegaram à África e ao depararem-se com os negros, eles não aceitaram os negros como seus semelhantes de espécie, exatamente pelo fato de comportarem-se como parte da natureza. A visão que os colonizadores tinham dos negros, conforme relata Arendt, era: o que tornava-os diferentes dos outros seres humanos não era absolutamente a cor da pele, mas o fato deles se comportarem como parte da natureza.

Na mesma linha de raciocínio desse debate e atribuindo o mesmo sentido, Santos (2005, p. 29) comenta que "um dos acontecimentos mais importantes dos séculos XVIII ao XX, foi à invenção do selvagem como ser inferior e a imposição da idéia de progresso científico e tecnológico como imperativo para atingir o estágio supremo do desenvolvimento - a Civilização Ocidental".

Do ponto de vista do olhar colonizador, tanto o "selvagem" como a "natureza" não tinham outro sentido, se não domesticar para dominar e em seguida explorar até as últimas conseqüências.

Por sua vez, a construção da natureza como algo exterior à sociedade uma construção estranha aos povos com que os europeus entravam em contato - obedeceu às exigências da constituição do novo sistema econômico mundial, centrado na exploração intensiva dos recursos. Esta construção foi sustentada por um processo que veio a ser conhecido como Revolução Científica, e esteve na origem da ciência tal como hoje a conhecemos, a ciência moderna. De Galileu a Newton, de Descartes a Bacon, um novo paradigma científico emerge, que separa a natureza da cultura e da sociedade e submete a primeira a um guião determinístico em que a linguagem matemática assume um papel central enquanto recurso para tornar inteligível uma natureza que, sendo tão incompreensível, como interlocutor, quanto o selvagem que habitava as paragens ocupadas e conquistadas pelos ocidentais, não podia ser compreendida; podia apenas ser explicada, sendo essa explicação a tarefa da ciência moderna (SANTOS, 2005, p. 26.). 
Nesse sentido, surge e se consolida no campo do conhecimento científico uma visão ambiental com base na fragmentação entre natureza e sociedade e que desconsidera a relação existente de interdependência entre a cultura humana e o mundo natural.

Essa visão ambiental que oculta à interdependência entre a sociedade e a natureza ocupou um espaço hegemônico no campo da EA, ao mesmo tempo, em que afirmou a sua inserção e legitimidade na sociedade.

Como características mais expressivas dessa concepção de EA, que nomeamos como EA conservadora ou comportamentalista, destacaríamos que o seu enfoque quanto ao tratamento da questão ambiental, apresenta uma compreensão naturalista e conservacionista da crise ambiental; aborda uma visão reducionista, biologizante ou fragmentada da questão ambiental; compreende a natureza como algo exterior que rodeia a vida humana.

No que diz respeito ao seu enfoque na relação da sociedade com a natureza, destaca-se a inexistência ou pouca ênfase na problematização dos processos históricos e sociais com a crise ambiental; apresenta dicotomia entre as dimensões sociais e naturais na problemática ambiental. Quanto aos indivíduos na sociedade, essa abordagem torna-os acríticos ou com pouco entusiasmo para se defrontar com os problemas socioambientais. Persegue a realização pessoal e tem o meio ambiente como forma de propiciar conforto e bem estar.

A educação nessa perspectiva é voltada para o "eu" na sua dimensão individual, isolado da sociedade, foca-se em vivências práticas em contato direto com a natureza como um fim em si mesmo; destaca-se pela despolitização do fazer pedagógico; a educação é um meio para salvar a natureza; na maioria das vezes, apóia-se em pedagogias comportamentalistas ou alternativas de cunho místico; a perspectiva crítica é inexistente; realiza-se com pouca incorporação ou inexistência de princípios e práticas interdisciplinares, além de se aproximar da educação bancária ii.

Nessa perspectiva de EA, as soluções dos problemas ambientais concentram-se nos próprios recursos tecnológicos; as aulas teóricas e práticas desenvolvem-se pelo enfoque meramente ecologizante, desconectando-se ou diluindo-se as discussões econômicas, políticas, culturais e sociais. As principais atividades pedagógicas direcionam-se para as visitas a ecossistemas naturais, diferenciando o meio urbano como se não fosse ambiente; atividades relacionadas a limpeza do lugar, reciclagem, coleta seletiva, plantação de mudas, economia da água, destaques para aspectos da fauna e da flora de maneira descontextualizada e despolitizada sobre a questão.

Dentro desta perspectiva, o educador, que não busca uma ação intencional de uma reflexão crítica, tende a reproduzir um discurso "ambientalizado". Esse discurso em construção que acompanha essas práticas ingênuas é um mecanismo de hegemonização de uma postura conservadora para uma Educação Ambiental que vem se estabelecendo na realidade escolar. [...] Esse discurso e essas 
práticas que vêm sendo denominados de Educação Ambiental são reflexos da cooptação, da racionalidade dominante que suprime, no ambiente escolar, a dimensão política em sua intencionalidade de gerar práticas críticas e criativas, como causa e conseqüência de uma reflexão crítica (GUIMARÃES, 2003, p. 95).

Por privilegiar uma visão fragmentadora e reducionista da questão ambiental, os resultados esperados dessa abordagem, são: negligenciar as implicações de ordens sociais; reforçar e reproduzir a ordem social vigente e, conseqüentemente, a perpetuação dos agravos ambientais e sociais. Além disso, a tendência conservadora ou comportamentalista se esvazia de sentido quanto aos seus objetivos e os resultados de um projeto de intervenção social pelas vias da educação.

Quanto aos riscos dessa visão e perspectiva de EA, Carvalho (2006, p. 37) afirma que "a conseqüência de uma visão predominantemente naturalista-conservacionista é a redução do meio ambiente a apenas uma de suas dimensões, desprezando a riqueza da permanente interação entre a natureza e a cultura humana". De fato, essa visão dificulta a compreensão de como a EA se insere na constituição de valores que levam a reprodução da sociedade ou a edificação de novos patamares societários.

A EA conservadora constitui-se como uma prática pedagógica que, por sua natureza, procura mudar os indivíduos, mas sem mudar o ambiente e o meio onde se inserem os indivíduos, camuflando a realidade e desviando os verdadeiros focos dos problemas que aborda.

Em nome do pragmatismo, da ética, e da sustentabilidade, a qual ninguém sabe de que, a EA conservadora ou comportamentalista enseja mudanças comportamentais nos indivíduos supondo que a crise ambiental é originada independente e desconectada das práticas sociais. Essa perspectiva ingenuamente acredita que só o "cada um faz a sua parte" é suficiente para se atingir uma sociedade equitativamente justa e ambientalmente sadia.

Tais fundamentos levam-nos a afirmar que, na prática educativa, essa perspectiva é ingênua, inócua de sentido, pois promete outro mundo sem confrontar-se com a realidade, procurando, principalmente, moldar a mentalidade dos indivíduos na sociedade para atuarem conservando e preservando o meio estritamente físico, mas sem transformar as mesmas condições sociais que agridem o meio físico e oprimem os indivíduos.

No cenário social atual, a EA pode vir a se constituir como recurso possível de transformação da realidade e, assim, ser entendida como um processo educativo de dimensão política que pode ser traduzido numa "práxis educativa e social que tem por finalidade a construção de valores, conceitos, habilidades e atitudes que possibilitem o entendimento da realidade de vida e atuação lúcida e responsável de atores sociais individuais e coletivos no ambiente" (LOUREIRO, 2002a, p. 69).

Pelo seu teor e vigor, a EA pode vir a ser um instrumento que reforce e incentive a viabilidade da inserção das discussões ambientais no âmbito da educação formal e popular. É com essa 
perspectiva, que ascende no campo da educação, a EA crítica como um processo permanente, cotidiano e coletivo pelo qual o sujeito reflete e age, almejando a transformação da realidade socioambiental, com vistas a construção de sociedades sustentáveis.

No âmbito desse contexto social atual e em sintonia com o pensamento de Paulo Freire (2000, p. 110) no qual "a educação é uma forma de intervenção no mundo", Lima (2002), Layrargues (2004a; 2004b), Loureiro et al (2002b; 2006), Loureiro (2004), reforçam formulações teóricas que consolidam, no campo da educação, a Educação Ambiental numa perspectiva crítica.

Essa visão de EA permite compreender que, mesmo diante da barbárie, é possível pensar sobre o papel social da escola e o seu lugar quanto a construção de um futuro melhor. Nesse cenário, a educação é, para Layrargues (2006, p. 76):

um dos espaços - políticos - onde se travam as disputas ideológicas entre os grupos antagônicos, onde as forças sociais hegemônicas procuram manter o status quo, enquanto as forças sociais contra-hegemônicas procuram alterá-lo. [...] a educação é um campo de disputa que cumpre um papel de desalienação ideológica das condições sociais, evidenciando que as coisas nem sempre foram assim, e que não têm porque continuarem assim sendo.

É principalmente no interior de uma concepção que está mais inserida nos debates políticos do campo da educação pela dialética, em suas diferentes formulações de caráter marxista ou numa estreita relação com suas categorias, associada às contribuições da teoria crítica, que surge a EA crítica. Por sua natureza epistemológica, essa pedagogia também se caracteriza como uma práxis Transformadora ou Emancipatória, como uma tendência que se contrapõe às práticas reducionistas, fragmentadoras, marcadas principalmente por seus aspectos biologizante e ecologizante que dilui ou desconecta as discussões econômicas, políticas, culturais e sociais da questão ambiental.

Nessa perspectiva de EA que opera pela dialética e suas categorias, sociedade e natureza coexistem com a práxis histórica. Loureiro (2006, p. 138) esclarece que "a visão que o marco teórico emancipatório em Educação Ambiental tem da humanidade é que esta é a unidade dialética com a natureza, em que os sujeitos são pensados concretamente e não abstratamente". Essa concepção enfatiza a educação como um processo político permanente, cotidiano, individual e coletivo pelo qual agimos e refletimos transformando a realidade de vida para a coletividade.

Enquanto parte integrante de um processo educacional mais abrangente, a EA crítica está consolidando-se como "uma tendência que está focada na pedagogia do conflito, no princípio da incertezaii, como forma de se estabelecer movimentos emancipatórios e políticos de transformação social" (LOUREIRO, 2006, p. 141). É uma práxis, no pensamento de Guimarães (2006, p. 27), que "para causar transformações significativas, deve superar as perspectivas individualizantes realizando-se no coletivo pelo coletivo". Portanto, é para Loureiro (2004, p. 89) uma EA "que possui um conteúdo emancipatório, em que a dialética, entre forma e 
conteúdo, realiza-se de tal maneira que as alterações da atividade humana, vinculadas ao ato educativo, impliquem mudanças individuais e coletivas, locais e globais, estruturais e conjunturais, econômicas e culturais".

Ao contrário da EA conservadora, no que concerne a compreensão da questão ambiental, a EA crítica problematiza, politiza e publiciza o debate, além de promover a inseparabilidade da questão ambiental da questão social. O enfoque quanto aos indivíduos na sociedade é de que eles devem superar sempre as perspectivas individualizantes, típicas de uma sociedade capitalista. As ações dos sujeitos realizam-se na sociedade no coletivo pelo coletivo, almejando a autonomia, a criatividade transformadora e liberdades humanas. Nessa perspectiva, a educação é compreendida como um processo permanente, cotidiano e coletivo pelo qual o sujeito constrói suas ações, refletindo, agindo e transformando a realidade de vida; a educação é entendida pela ótica democrática, da autogestão, com a convicção de que a participação social e o exercício da criticidade são práticas indissociáveis dos processos educativos. Propõe-se a desenvolver e estimular a atitude crítica diante dos desafios da crise socioambiental conjuntamente com a vocação transformadora dos valores e práticas contrárias ao bem-estar público e coletivo. Essa tendência busca estimular o diálogo entre as ciências e os saberes tradicionais com o devido cuidado em não tratar separadamente as ciências e nem negar o saber das tradições e da cultura popular.

Na EA crítica, as soluções dos problemas socioambientais são vistos a partir da dinâmica do modo de produção capitalista, desassociando os processos de produção e consumo, ética, tecnologia do contexto sócio-histórico, dos interesses individuais e coletivos e públicos e privados.

Os conteúdos e as atividades práticas, no interior da escola ou nos processos não formais de ensino, buscam sempre a contextualização dos temas geradores de discussão, sem objetivar o ensinamento como um fim em si mesmo, mas levando à reflexão sobre a crise socioambiental, remetendo-as sempre a perspectivas de mudança social para se atingir a mudança ambiental.

Essa perspectiva de EA busca perseguir a vocação transformadora dos sujeitos que atuam na história modificando-a e sendo transformados em processos alternativos ou contrahegemônicos ao modo como a sociedade está organizada. E quanto ao status quo, deseja transformá-lo.

A EA Crítica de caráter transformador e emancipatória é oposta à Educação Ambiental conservadora de cunho meramente biologizante e ecologizante que fragmenta, reduz ou omite a dimensão social da questão ambiental. Essa perspectiva aponta os limites da Educação Ambiental conservadora, que subjuga a ação humana ao tecido social e nega, ao mesmo tempo, a existência de um sujeito histórico transformador da realidade de vida. 


\section{CONSIDERAÇÕES FINAIS}

No decorrer do artigo, buscamos resgatar e compreender os antecedentes contextuais da história e da sociedade que contribuíram com o surgimento do campo ambiental e sua dimensão política, bem como da Educação Ambiental, enquanto sua parte constitutiva e estratégica em busca de novos sentidos para a vida e para a sociedade.

Esse artigo não tenta esboçar uma conclusão definitiva sobre os aspectos discutidos pelo fato de estarmos continuamente no processo de exploração cognitiva, emotiva e política sobre a temática em questão que, por sua vez, ainda é bastante embrionária.

Não estamos com isso, propondo a uniformização da EA, ao contrário, acreditamos que deve ser exercida explorando-se a criatividade e a imaginação dos educadores e dos educandos, mas demonstramos que, no âmbito das escolas, a EA realiza-se de maneira bastante diversificada quanto aos objetivos, sentidos e significados bem distantes de uma proposta que pudesse, de fato, se situar dentro de uma pedagogia crítica, transformadora e emancipatória.

Nesse sentido, a constituição de uma Educação Ambiental crítica, transformadora, emancipatória não se faz presa à armadilha da visão que subordina a função social da educação, como tem sido aprisionada historicamente de forma planejada e controlada, apenas para atender as demandas e os interesses do capital.

A Educação Ambiental aqui assumida e proposta à sociedade é oposta à Educação Ambiental conservadora consolidada, no nosso entendimento em outro momento (GONZAGA, 2008, p. 129) como "uma prática pedagógica que escamoteia os conflitos sociais, que esconde as mazelas da periferia e cria outros focos de vizibilização vista a não permitir se enxergar as contradições do modo de produção capitalista".

\section{REFERÊNCIAS BIBLIOGRÁFICAS}

1. ARENDT, H. Origens do totalitarismo. São Paulo: Companhia das Letras, 1989.

2. CARVALHO, I. C. M. Educação ambiental: a formação do sujeito ecológico. 2. ed. São Paulo: Cortez, 2006. (Coleção Docência em formação).

3. DIAS, Genebaldo Freire. Educação ambiental: princípios e práticas. 9. ed. São Paulo: Gaia, 2004.

4. FREIRE, Paulo. Pedagogia da autonomia: saberes necessários à prática educativa. São Paulo: Paz e Terra, 2000.

5. GERMANO, José Willington. Estado militar e educação no Brasil: 1964-1985. 2. ed. São Paulo: Cortez, 1994.

6. GONÇALVES, Carlos W. P. Meio ambiente, ciência e poder: diálogo de diferentes matrizes de racionalidade. In: SORRENTINO, M. (Coord.). Ambientalismo e participação na contemporaneidade. São Paulo: EDUC/FAPESP, 2002.

7. GONZAGA, M. J. B. Educação Ambiental: um estudo de experiências em escolas municipais de Natal. 2008. 160 f. Dissertação (Mestrado em Ciências Sociais) - Programa de Pós-Graduação em 
Ciências Sociais, Centro de Ciências Humanas, Letras e Artes, Universidade Federal do Rio Grande do Norte, Natal, 2008.

8. GUIMARÃES, Mauro. Educadores ambientais em uma perspectiva crítica: reflexões em Xerém. 2003. 179f. Tese (Doutorado em Desenvolvimento, Agricultura e Sociedade) - Universidade Federal Rural do Rio de Janeiro, Rio de Janeiro, 2003.

9. GUIMARÃES, Mauro. Armadilha paradigmática na educação ambiental: In: LOUREIRO, C. F. B. at al. Pensamento complexo, dialética e educação ambiental. São Paulo: Cortez, 2006.

10. LAYRARGUES, P. P. Educação para gestão ambiental: a cidadania no enfrentamento político dos conflitos socioambientais. In: LOUREIRO, C. F. B. et al. Sociedade e meio ambiente: a educação ambiental em debate. 3. ed. São Paulo: Cortez, 2002.

11. LAYRARGUES, P. P. Para que a educação ambiental encontre a educação. In: LOUREIRO, C. F. B. Trajetória e fundamentos da educação ambiental. São Paulo: Cortez, 2004a.

12. LAYRARGUES, P. P. (Coord.). Identidades da educação ambiental brasileira. Brasília: Ministério do Meio Ambiente, 2004b.

13. LAYRARGUES, P. P. (Coord.). Identidades da educação ambiental brasileira. Brasília: Ministério do Meio Ambiente, 2004b.

14. LAYRARGUES, P. P. Muito além da natureza: educação ambiental e reprodução social. In: LOUREIRO, C.F.B. et al. Pensamento complexo, dialética e educação ambiental. São Paulo: Cortez, 2006.

15. LIMA, G. F. C. Crise Ambiental, educação e cidadania: os desafios da sustentabilidade emancipatória. In: LOUREIRO, C. F. B.; LAYRARGUES, P. P.; CASTRO, R. S. (Org.). Educação ambiental: repensando o espaço da cidadania. 2. ed. São Paulo: Cortez, 2002.

16. LIMA, G. F. C. Formação e dinâmica do campo da educação ambiental no Brasil: emergência, identidades e desafios. 2005. 207f. Tese (Doutorado em Ciências Sociais) - Instituto de Ciências Humanas e Sociais, Universidade Estadual de Campinas, Campinas, 2005.

17. LOUREIRO, C. F. B. Trajetória e fundamentos da educação ambiental. São Paulo: Cortez, 2004.

18. . Pensamento complexo, dialética e educação ambiental. São Paulo: Cortez, 2006.

19. LOUREIRO, C. F. B. et al. Educação ambiental: repensando o espaço da cidadania. 2. ed. São Paulo: Cortez, 2002a.

20. . Sociedade e meio ambiente: a educação ambiental em debate. 3. ed. São Paulo: Cortez, 2002b.

21. SANTOS, B. S. et al. Introdução: Para ampliar o cânone da ciência: a diversidade epistemológica do mundo. In: SANTOS, B. S. et al. Semear outras soluções: os caminhos da biodiversidade e dos conhecimentos rivais. Rio de Janeiro: Civilização, 2005.

22. SAUVÉ, Lucien. Uma cartografia das correntes em educação ambiental. In: SATO M.; CARVALHO, I.C. (Org.). Educação ambiental: pesquisa e desafios. Porto Alegre: Artmed, 2005.

\footnotetext{
${ }^{i}$ Vale destacar que na Lei 6.902/81, a educação é direcionada para o campo da ecologia com um sentido conservacionista explícito, não sendo ainda mencionada a Educação Ambiental.

ii No sentido atribuído por Freire (1988).

iii Princípio da incerteza de Heizenberg
} 